\title{
An Approximate Method for Permuting Frame with Repeated Lattice Structure to Equivalent Beam
}

\author{
H.I. Park ${ }^{\mathrm{a}, *}$ and C.G. Park ${ }^{\mathrm{b}}$ \\ ${ }^{a}$ Department of Ocean Engineering, Korea Maritime University, Busan 606-791, Korea \\ ${ }^{b}$ Ocean Engineering Division, Samsung Heavy Industries, Keoje 656-710, Korea
}

\begin{abstract}
In this paper, equivalent stiffness and mass matrices of a beam to a frame with repeated lattice structure are obtained to permute a frame to an equivalent continuous beam. Static and dynamic results of the permutated beam are obtained and compared to ANSYS's results for the original frames with good agreements. The technique can be usefully employed for analyzing the global behavior of a frame by permuting to a beam. The technique also leads to reducing significantly the degrees of freedom of frames and thus the computing time in their dynamic analysis.
\end{abstract}

Keywords: Frame, Beam permutation, Reduction of degree of freedom, Equivalent stiffness and mass matrices.

\section{INTRODUCTION}

Many offshore and land structures such as guyed towers, cranes booms, bridges and tall buildings are framed structures which consist of repeated lattice structures with a lot of discrete members. Obtaining static and dynamic responses of a frame mostly relies on numerical methods. Carrying out full-scale structural analysis for large frames requires much computational time, storage spaces and associated expanse. Approximate methods with sufficient accuracy for conducting structural analysis of large frames are of great value, especially during an iterative and preliminary design stage.

There have been numerous studies on reducing the degrees of freedom of the structures with many discrete members. Noor [1], Necib and Sun [2] and Sun and Juang [3] proposed continuum models with repeating lattice structures based on an equivalent energy method. Noor's model [1] replaced displacements and strain of the lattice structure by Taylor series expansions, based on the complicated kinetic relations and some assumptions. The model used by Necib and Sun [2] and Sun and Juang [3] is a Timoshenko beam which has 12 by 12 stiffness matrix for plane problems. Similar methods were also proposed for the structural analysis of tall buildings by Chajes et al. $[4,5]$ using a reduced order continuum model with 9 degrees of freedom for plane problems.

The authors developed a basic technique of permuting a frame to an equivalent in the previous work (Piao and Park, [6]). In this paper, the technique is further advanced for the analysis of static and dynamic responses of a frame. This technique is relatively simpler than other methods for reducing the degree of freedom of frames. The technique is useful for analyzing the global behavior of a frame by permuting to a beam, while it leads to reducing computing time and

*Address correspondence to this author at the Department of Ocean Engineering, Korea Maritime University, Busan 606-791, Korea;

Tel: (82-51) 410-4326; Fax: (82-51) 403-4320; E-mail : hipark@hhu.ac.kr associated storage spaces required in structural analysis of frames. This technique can be applied to a frame with linearly varying cross sections as well as with same cross sections.

\section{DERIVATION OF EQUIVALENT STIFFNESS AND MASS MATRICES}

For a structural analysis, stiffness and inertia terms are basically required in the governing equation. In the following, the derivation procedure of obtaining equivalent stiffness and mass matrices of a beam to a frame with repeated lattice structure is described.

\subsection{Derivation of Equivalent Stiffness Matrix}

The procedure of deriving equivalent stiffness matrix of a beam to a frame segment is as follows. First, a typical segment is isolated from an original frame with an assumption that each end cross-section remains in a plane. Fig. (1) shows a frame model, isolated segment frame and the node numbers on an end section. Then the stiffness matrix of the segment is derived based on the definition of stiffness of a beam element that the forces required to obtain the unit displacement for the degree of freedom with all other degrees of freedom restrained to zero displacement.

For a three-dimensional frame segment, a node located on an end cross-section of the frame segment has six degrees of freedom. It is imposed that the node on an end crosssection moves along the global axis $\mathrm{X}$ or $\mathrm{Y}, \mathrm{Z}$, or rotates about the axis $\mathrm{X}$ or $\mathrm{Y}, \mathrm{Z}$ to form unit displacements.

These displacements of the nodes located on an end cross-section of the frame segment can be expressed as ID $(i, j, k)$ in a matrix form which is referred as an imposed displacement matrix here, where $i(1 \sim 6)$ represents the directions of three displacements of $\mathrm{X}, \mathrm{Y}$ and $\mathrm{X}$ directions and three rotations about $\mathrm{X}, \mathrm{Y}$ and $\mathrm{X}$ axis, $j(1 \sim 6)$ does the degrees of freedom of each node and $k$ does node numbers on an end cross-section in the segment. 


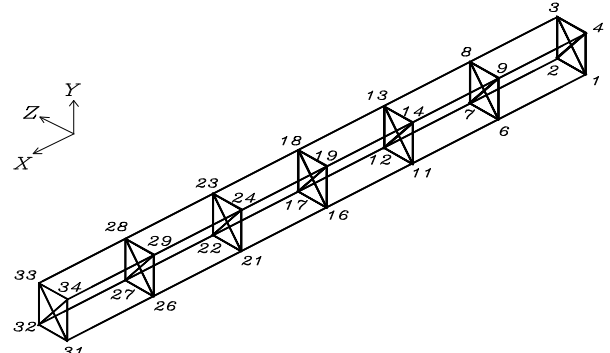

(a)

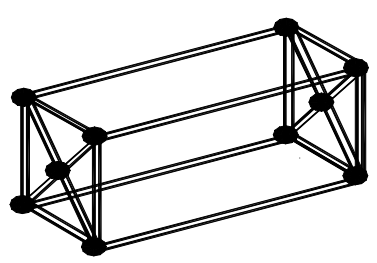

(b) (c)

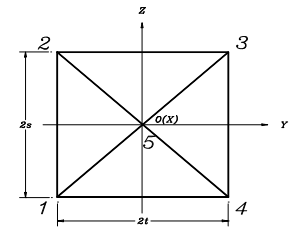

Fig. (1). Frame model (a), frame segment (b) and node numbers on a section $(\mathbf{c})$.

For each translation direction of the equivalent beam element where $i$ equals to1, 2, and 3, respectively, only the elements of the imposed displacement matrix ID corresponding to the translation direction for the nodes located on the end cross-sections have unit values, when the other elements of ID remain zero. For example, if the segment has unit displacement in $\mathrm{X}$ direction $(i=1)$, all the five nodes on an end section will have one degree of freedom in $\mathrm{X}$ direction and the other degree of freedom will be zero. In the matrix equation below, the column indicates the node numbers and row does the degree of freedom.

$\mathbf{I D}(1, \mathrm{j}, \mathrm{k})=\left[\begin{array}{ccccc}1 & 1 & 1 & 1 & 1 \\ 0 & 0 & 0 & 0 & 0 \\ 0 & 0 & 0 & 0 & 0 \\ 0 & 0 & 0 & 0 & 0 \\ 0 & 0 & 0 & 0 & 0 \\ 0 & 0 & 0 & 0 & 0\end{array}\right]$

If the frame section has different node numbers, the column numbers of the matrix will be changed.

For X-directional translation degree of freedom $((i=1)$, a general form of the imposed displacement matrix can be written in a compact form as follows.

$\mathbf{I D}(1, \mathrm{j}, \mathrm{k})= \begin{cases}1 & \text { when } \mathrm{j}=1 \\ 0 & \text { otherwise }\end{cases}$

For Y-direction $(i=2)$ :

$\operatorname{ID}(2, j, k)= \begin{cases}1 & \text { when } \mathrm{j}=2 \\ 0 & \text { otherwise }\end{cases}$

and for Z-direction $(i=3)$ :

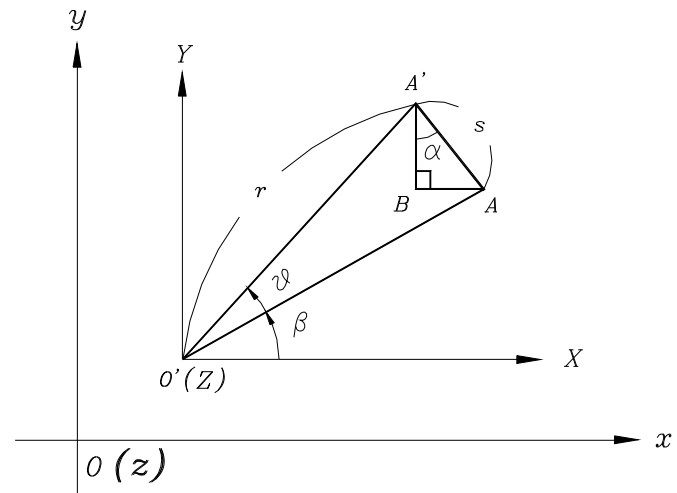

Fig. (2). Rotation of an arbitrary point.

$\mathbf{I D}(3, \mathrm{j}, \mathrm{k})= \begin{cases}1 & \text { when } \mathrm{j}=3 \\ 0 & \text { otherwise }\end{cases}$

In the case of rotation about $\mathrm{X}$-, $\mathrm{Y}$ - or $\mathrm{Z}$-axis, it is rather complex to obtain the imposed displacement matrix. For example, in the case of rotating about axis $\mathrm{Z}(i=6)$, the submatrix ID $(6, j, k)$ of the imposed displacement matrix can be derived as follows. Let an arbitrary point $\mathrm{A}\left(\mathrm{x}_{\mathrm{A}}, \mathrm{y}_{\mathrm{A}}, \mathrm{z}_{\mathrm{A}}\right)$ on an end cross-section of the frame segment rotates an angle $\theta$ (ex. $\theta=1 \mathrm{rad}$ ) in counter-clockwise about the geometric center of the end-section, O' (aa, bb, cc) (see Fig. 2). Here aa, bb, cc are the distances from $\mathrm{O}$ to $\mathrm{O}^{\prime}$ in $\mathrm{X}, \mathrm{Y}, \mathrm{Z}$ directions respectively.

Then the coordinate changes of the point $\mathrm{A}$ are

$$
\begin{aligned}
& \Delta \mathrm{x}_{\mathrm{Z}}=-\overline{\mathrm{BA}}=-\mathrm{s} \sin \alpha=-\left[\left(\mathrm{y}_{\mathrm{A}}-\mathrm{bb}\right) \sin \theta+\left(\mathrm{x}_{\mathrm{A}}-\mathrm{aa}\right)(1-\cos \theta)\right] \\
& \Delta \mathrm{y}_{\mathrm{Z}}=\overline{\mathrm{BA}^{\prime}}=\mathrm{s} \cos \alpha=\left[\left(\mathrm{x}_{\mathrm{A}}-\mathrm{aa}\right) \sin \theta-\left(\mathrm{y}_{\mathrm{A}}-\mathrm{bb}\right)(1-\cos \theta)\right] \\
& \Delta \mathrm{z}_{\mathrm{Z}}=0 \\
& \Delta \beta_{\mathrm{Z}}=\theta
\end{aligned}
$$

where

$$
\begin{aligned}
& \mathrm{s}=\overline{\mathrm{AA}^{\prime}}=2 \mathrm{r} \sin (\theta / 2) \\
& \mathrm{r}=\overline{\mathrm{OA}^{\prime}}=\overline{\mathrm{OA}^{\prime}} \\
& \alpha=\pi / 2-[(\pi-\theta) / 2-\beta]=\beta+\theta / 2
\end{aligned}
$$

Eqs. (4) to (7) correspond to the components of $\operatorname{ID}(6, j, k)$ for $j=1,2,3,6$, respectively, and the other elements of ID $(6, j, k)$ for $j=4,5$ are zero, provided that the angle $\theta$ equals 1 radian.

For the case of point A being rotated about axis $\mathrm{Y}(j=5)$, the components of $\mathbf{I D}(5, j, k)$ can be obtained in a similar way. That is to say, the components of $\mathbf{I D}(5, j, k)$ can be obtained by replacing the $\mathrm{X}, \mathrm{Y}$, and Z by Z, X, and Y in Eqs. (4) to (7) respectively, as follows.

$$
\begin{aligned}
& \Delta \mathrm{z}_{\mathrm{Y}}=-\left[\left(\mathrm{x}_{\mathrm{A}}-\mathrm{aa}\right) \sin \theta+\left(\mathrm{z}_{\mathrm{A}}-\mathrm{cc}\right)(1-\cos \theta)\right] \\
& \Delta \mathrm{x}_{\mathrm{Y}}=\left[\left(\mathrm{z}_{\mathrm{A}}-\mathrm{cc}\right) \sin \theta-\left(\mathrm{x}_{\mathrm{A}}-\mathrm{aa}\right)(1-\cos \theta)\right] \\
& \Delta \mathrm{y}_{\mathrm{Y}}=0
\end{aligned}
$$




$$
\Delta \beta_{\mathrm{Y}}=\theta
$$

Also for the point A rotating about axis $X(i=4)$, the $X$, $\mathrm{Y}$, and Z in Eqs. (4) to (7) should be replaced by $\mathrm{Y}, \mathrm{Z}$, and $\mathrm{X}$ respectively, as follows.

$$
\begin{aligned}
& \Delta \mathrm{y}_{\mathrm{X}}=-\left[\left(\mathrm{z}_{\mathrm{A}}-\mathrm{cc}\right) \sin \theta+\left(\mathrm{y}_{\mathrm{A}}-\mathrm{bb}\right)(1-\cos \theta)\right] \\
& \Delta \mathrm{z}_{\mathrm{X}}=\left[\left(\mathrm{y}_{\mathrm{A}}-\mathrm{bb}\right) \sin \theta-\left(\mathrm{z}_{\mathrm{A}}-\mathrm{cc}\right)(1-\cos \theta)\right] \\
& \Delta \mathrm{x}_{\mathrm{X}}=0 \\
& \Delta \beta_{\mathrm{X}}=\theta
\end{aligned}
$$

As the second step, for the each case above, the reaction vector $\mathbf{R}_{s}$ of the nodes located on two end cross-sections of the frame segment is calculated by using a simple numerical code. In the calculation of the reaction vector, the boundary condition is treated as fixed. In order to form the stiffness coefficients of the corresponding degrees of freedom, the reaction vector is then transformed to an equivalent force vector at a geometric center of end cross-section by using the following transformation relation. The transformation relation of forces $\left(\mathrm{F}_{\mathrm{X}}, \mathrm{F}_{\mathrm{Y}}, \mathrm{F}_{\mathrm{Z}}, \mathrm{M}_{\mathrm{X}}, \mathrm{M}_{\mathrm{Y}}, \mathrm{M}_{\mathrm{Z}}\right)$ of any point $(\mathrm{x}, \mathrm{y}, \mathrm{z})$ to equivalent ones $\left(\mathrm{F}_{\mathrm{X}}{ }, \mathrm{F}_{\mathrm{Y}}{ }_{\mathrm{Y}}, \mathrm{F}_{\mathrm{Z}}{ }_{\mathrm{Z}}, \mathrm{M}_{\mathrm{X}}{ }_{\mathrm{X}}, \mathrm{M}_{\mathrm{Y}}{ }_{\mathrm{Y}}, \mathrm{M}_{\mathrm{Z}}{ }_{\mathrm{Z}}\right)$ at the origin is

$$
\left[\begin{array}{cccccc}
1 & 0 & 0 & 0 & 0 & 0 \\
0 & 1 & 0 & 0 & 0 & 0 \\
0 & 0 & 1 & 0 & 0 & 0 \\
0 & -\mathrm{Z} & \mathrm{y} & 1 & 0 & 0 \\
\mathrm{z} & 0 & -\mathrm{x} & 0 & 1 & 0 \\
-\mathrm{y} & \mathrm{y} & 0 & 0 & 0 & 1
\end{array}\right]\left\{\begin{array}{l}
\mathrm{F}_{\mathrm{X}} \\
\mathrm{F}_{\mathrm{Y}} \\
\mathrm{F}_{\mathrm{Z}} \\
\mathrm{M}_{\mathrm{X}} \\
\mathrm{M}_{\mathrm{Y}} \\
\mathrm{M}_{\mathrm{Z}}
\end{array}\right\}=\left\{\begin{array}{l}
\mathrm{F}^{\prime}{ }_{\mathrm{X}} \\
\mathrm{F}^{\prime}{ }_{\mathrm{Y}} \\
\mathrm{F}^{\prime}{ }_{\mathrm{Z}} \\
\mathrm{M}^{\prime}{ }_{\mathrm{X}} \\
\mathrm{M}^{\prime}{ }_{\mathrm{Y}} \\
\mathrm{M}_{\mathrm{Z}}{ }_{\mathrm{Z}}
\end{array}\right\}
$$

or

$$
\mathbf{T} \cdot \mathbf{F}=\mathbf{F}^{\prime}
$$

where the matrix $\mathbf{T}$ is a transformation matrix for one node. Hence the transformation matrix can be exactly expanded for other nodes on an end cross-section.

As the final step, these transformed forces are combined along each degrees of freedom of the geometric center of the end cross-section. Then the resulting forces are the stiffness elements along each degree of freedom of the equivalent beam element as follows.

$\mathbf{K e}=\mathbf{T} \cdot \mathbf{R}_{\mathrm{s}}$

where Ke is a stiffness matrix of the equivalent beam element.

In this study, the derived stiffness matrix of an equivalent beam element will be 12 by 12 since the Euler-Bernoulli beam theory is adopted.

\subsection{Derivation of Equivalent Mass Matrix}

In the previous section, equivalent stiffness matrix was derived using a static governing equation. Similarly, equivalent mass matrix can be derived using a dynamic governing equation.

$\mathbf{M} \ddot{\mathbf{x}}=\mathbf{F}$
As for the case of equivalent stiffness matrix, the imposed acceleration matrix $\mathbf{I A}(i, j, k)$ of the nodes located on one end cross section of the segment corresponding to unit acceleration along $i$ th degree of freedom of the equivalent beam element can be calculated. The matrix IA is obtained in acceleration field and the unit translation and rotational accelerations can be obtained by the same procedure applied to the unit displacements. So, one can see that the resulting imposed acceleration matrix IA is the same as ID for the equivalent stiffness matrix.

$\mathbf{I A}(i, j, k)=\mathbf{I D}(i, j, k)$

For the imposed accelerations of each degree of freedom of the equivalent beam element, the reaction vector of the nodes located on two end cross sections of the original frame segment is calculated under the boundary condition of fixed ends as was done for the case of equivalent stiffness matrix. Then the reaction vector $\mathbf{R}_{m}$ is transformed into equivalent force at the geometric centers of end cross sections by the following transformation relation to form the mass coefficients of corresponding degrees of freedom of the equivalent beam element.

$$
\mathbf{M}_{\mathrm{e}}=\mathbf{T} \cdot \mathbf{R}_{\mathrm{m}}
$$

where $\mathbf{M}_{\mathbf{e}}$ is the derived equivalent mass matrix of the segment and is a consistent mass of 12 by 12 order.

By using the beam permutation technique explained above, total degrees of freedom of frames can be significantly reduced. For example, if a frame segment has eight nodes and each end cross section contains four nodes, then total number of degrees of freedom of the segment is 48 , while a beam element has twelve degrees of freedom. Thus, the degrees of freedom can be reduced to one fourth of the original. This technique can be also applied to a frame with linearly varying cross sections.

\section{VERIFICATION AND DISCUSSION}

To verify the technique, the results of static analysis and modal analysis of an original frame are obtained and compared with those of the equivalently permuted beam. The response of the original frames is calculated by a wellknown structural analysis package, ANSYS.

In this verification, two different frame models are adopted shown in Fig. (3). Both models of A and B have ten segments of equal length and four nodes on the base are fixed. The model A is single-braced whereas the model B is double-braced. For convenience, the two models are composed of pipe members. The diameter of pipe member is $89.1 \mathrm{~mm}$, thickness is $3.5 \mathrm{~mm}$, and the elastic and shear modules are $210 \mathrm{GPa}$ and $88 \mathrm{GPa}$, respectively.

\subsection{Static Analysis}

Four static forces of $2500 \mathrm{~N}$ are equally loaded at four corner of the model's top end in lateral and axial directions. Both models are permuted to equivalent beams by using the present permutation technique and then their static displacements are obtained. The static displacements of the original frame models are directly obtained by using ANSYS pro- 


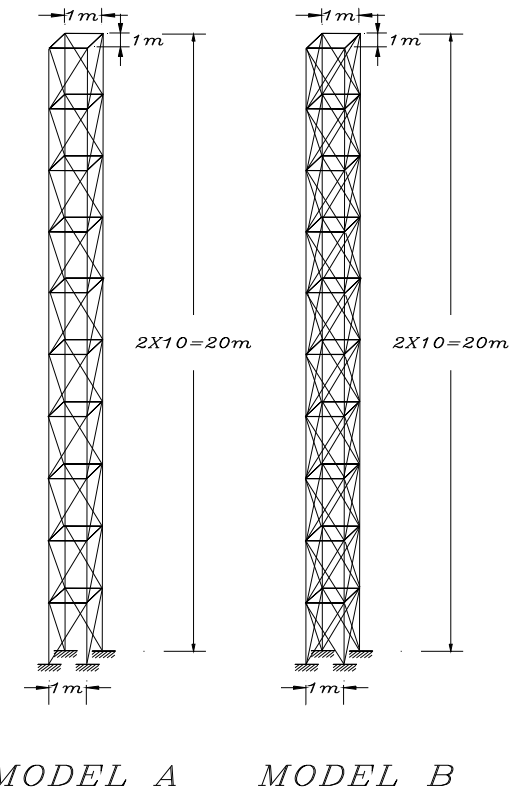

Fig. (3). Sketch of models.

Table 1. Comparison of Static Displacement Between Present Method and ANSYS for Model A

\begin{tabular}{|c|c|c|c|}
\hline \multirow{2}{*}{$\begin{array}{c}\text { Loading } \\
\text { Direction }\end{array}$} & \multicolumn{3}{|c|}{ End Displacement in Loading Direction (m) } \\
\cline { 2 - 4 } & $\begin{array}{c}\text { Present Method } \\
\text { for Permuted } \\
\text { Beam }\end{array}$ & $\begin{array}{c}\text { ANSYS } \\
\text { for Original } \\
\text { Frame }\end{array}$ & Deviation (\%) \\
\hline \hline X & $0.249 \mathrm{E}-3$ & $0.253 \mathrm{E}-3$ & 1.6 \\
\hline $\mathrm{Y}$ & 0.136 & 0.137 & -0.73 \\
\hline $\mathrm{Z}$ & 0.136 & 0.137 & -0.73 \\
\hline
\end{tabular}

Table 2. Comparison of Static Displacements Between Present Method and ANSYS for Model B

\begin{tabular}{|c|c|c|c|}
\hline \multirow{2}{*}{$\begin{array}{c}\text { Loading } \\
\text { Direction }\end{array}$} & \multicolumn{3}{|c|}{ End Displacement in Loading Direction (m) } \\
\cline { 2 - 4 } & $\begin{array}{c}\text { Present Method for } \\
\text { Permuted Beam }\end{array}$ & $\begin{array}{c}\text { ANSYS for } \\
\text { Original Frame }\end{array}$ & Deviation (\%) \\
\hline \hline X & $0.104 \mathrm{E}-3$ & $0.104 \mathrm{E}-3$ & 0 \\
\hline Y & 0.0807 & 0.0838 & -3.7 \\
\hline$Z$ & 0.0807 & 0.0838 & -3.7 \\
\hline
\end{tabular}

gram. The results of displacements at the top end of the models are presented in Tables $\mathbf{1}$ and $\mathbf{2}$. The maximum deviations between the two methods are less than $4.0 \%$. It can be concluded that the equivalent beam stiffness matrices of the two models are satisfactorily close to the stiffness matrices of original frame models.

\subsection{Modal Analysis}

In order to verify the equivalent mass matrix obtained by the permutation technique aforementioned, the natural fre-
Table 3. Comparison of Natural Frequencies $(\mathrm{Hz})$ Between Present Method and ANSYS for Model A

\begin{tabular}{|c|c|c|c|}
\hline Order & Present Method & ANSYS & Deviation (\%) \\
\hline \hline 1 & 2.2117 & 2.1677 & 2.0 \\
2 & 2.2122 & 2.1677 & 2.0 \\
\hline 3 & 12.734 & 12.401 & 2.7 \\
4 & 12.734 & 12.401 & 2.7 \\
\hline $5^{*}$ & 29.172 & 30.466 & -4.3 \\
\hline 6 & 31.630 & 30.632 & 3.3 \\
7 & 31.630 & 30.632 & 3.3 \\
\hline 8 & 49.683 & 50.503 & -1.6 \\
9 & 49.683 & 50.503 & -1.6 \\
\hline
\end{tabular}

Super script, * represents torsion vibration mode, while others are bending modes.

Table 4. Comparison of Natural Frequencies (Hz) Between Present Method and ANSYS for Model B

\begin{tabular}{|c|c|c|c|}
\hline Order & Present & ANSYS & Deviation (\%) \\
\hline \hline 1 & 2.4260 & 2.3396 & 3.7 \\
2 & 2.4263 & 2.3396 & 3.7 \\
\hline 3 & 14.1891 & 14.1891 & 2.5 \\
4 & 14.1891 & 14.1891 & 3.5 \\
\hline $5^{*}$ & 16.7538 & 16.529 & 1.4 \\
\hline 6 & 36.2783 & 36.125 & 0.42 \\
7 & 36.2785 & 36.125 & 0.42 \\
\hline $8^{*}$ & 50.3646 & 49.403 & 2.0 \\
\hline
\end{tabular}

quencies of the permuted beam need to be obtained and to compare with those of the original frame.

As was done in the static analysis, both frame models in Fig. (3) are permuted to equivalent beams by using the present permutation technique and then their natural frequencies of the beams are simply obtained. The natural frequencies of the original frame models are directly obtained by using commercial ANSYS software.

The natural frequencies of first few vibration modes of the permuted beams and the original frame models are presented in Tables $\mathbf{3}$ and $\mathbf{4}$ and compared each other with good agreements. The maximum deviations between the two methods are less than $4.3 \%$. It can be concluded that the equivalent beam mass and stiffness matrices of the two models are satisfactorily close to those of original frame models.

\section{CONCLUSIONS}

In this study, a technique of permuting a frame to an equivalent beam by obtaining an equivalent stiffness and mass matrices of a beam to a frame is introduced. The technique is verified by comparing static and modal analysis results for two different models by the present technique and ANSYS with good agreements. The technique is useful for 
analyzing the global behavior of a frame by permuting to a beam. It also leads to reducing the degrees of freedom of frames and thus the computing time in their structural analysis. This technique can be applied to a frame with linearly varying cross sections as well as same cross sections.

The present technique can be usefully employed in a preliminary design stage of frames. Further work is needed for frames with large displacements.

\section{ACKNOWLEDGEMENT}

This work is financially supported by the fund from Underwater Vehicle Research Center, Agency for Defense Development, needs to be included.

\section{REFERENCES}

[1] K. Noor, "Continuum modeling for repetitive lattice structures", Appl. Mech. Rev., vol. 41, pp. 285-296, 1988.

[2] Necib, and C. T. Sun, "Analysis of truss beam using high order Timoshenko beam finite element", J. Sound Vibr. vol. 130, no. 1, pp. $149-159,1989$

[3] J. Sun, and J. N. Juang, "Modeling global structural damping in trusses using simple continuum models", Am. Inst. Aeronautics Astronautics J., vol. 24, no. 1, pp. 144-150, 1986.

[4] M. J. Chajes, K. M. Romstad, and D. B. McCallen, "Analysis of multiple-bay frames using continuum model", J. Struct. Eng., vol. 119, no. 2, pp. 522-546, 1993.

[5] M. J. Chajes, L. Zhang, and J. T. Kirby, "Dynamic analysis of tall building using reduced-order continuum model", J. Struct. Eng., vol. 122, no. 11, pp. 1284-1291, 1996.

[6] J. Piao, H. I. Park, "A study on beam permutation technique for offshore structure", J. Ocean Eng. Technol., vol. 13, no. 1, pp. 2328, 1999. (in Korean).

(C) Park and Park et al.; Licensee Bentham Open.

This is an open access article licensed under the terms of the Creative Commons Attribution Non-Commercial License (http://creativecommons.org/licenses/by-nc/3.0/) which permits unrestricted, non-commercial use, distribution and reproduction in any medium, provided the work is properly cited. 